\title{
Diffusion of New Treatments in Community Practice: Recommendations for Implementation
}

\author{
Keith Klostermann ${ }^{1 *}$, Susan Steffan ${ }^{1}$, William Weeks ${ }^{1}$ and Theresa Mignone ${ }^{2}$ \\ ${ }^{1}$ Medaille College, USA \\ ${ }^{2}$ VA Western New York Healthcare System, USA \\ *Corresponding author: Keith Klostermann, Medaille College, Buffalo, New York, USA
}

Submission: 漹 April 02, 2018; Published: 漹 June 19, 2018

\begin{abstract}
Given increasing emphasis for the use of evidence-based treatment to psychological disorders, community providers are faced with the challenge of successfully implementing new practices. Although adopting a new approach may seem simple, empirical evidence reveals that $50 \%$ to $75 \%$ of all organization-wide change efforts fail. The need for effective implementation of new treatments is critical as patient well-being is directly impacted by the hopes and prayers of success or the realization of the proven failure rates of these kinds of efforts. The purpose of this commentary is to identify common implementation mistakes and provide recommendations for successful implementation.
\end{abstract}

\section{Introduction}

Given increasing emphasis for the use of evidence-based treatment to psychological disorders, the mandate for organizations is to implement these best-practice treatments in community practice. Although adopting a new approach may seem simple, successful implementation is much more complicated in reality. Simply stated, the question for practitioners and managers is, "how does a new treatment become the normal practice?" Many implementation efforts fail because of the lack of:

$$
\begin{array}{ll}
\text { I. Planning, } \\
\text { II. Communication, and } \\
\text { III. Feedback regarding successes and failures. }
\end{array}
$$

While these three poorly executed activities are certainly contributors to failed change efforts, there are more fundamental reasons for the high failure rate of change initiatives, which will be mentioned later in this paper. The purpose of this commentary is to identify common implementation mistakes along with recommendations for successful implementation. These mistakes are on two levels: the organizational approach to change and the actual interaction of the change approach with the content of the change itself.

Effecting change that lasts is a challenge and struggle for all organizations. This presents not only a struggle with "change that lasts" in the context of an environment of accelerated change and the shelf-life of current changes, but also a struggle to propose and implement a new approach to change in light of the empirical evidence that $50 \%$ to $75 \%$ of all organization-wide change efforts fail. When analyzed in the mental health practices, the need for effec tive implementation of changes has even higher stakes as patient well-being is directly impacted by the hopes and prayers of success or the realization of the proven failure rates of these kinds of efforts.

The first step in any content-based change process is to understand the current state, i.e. defining clearly and cogently the current reality of a number of things. An organization must define "what to change" before it can begin. An admonition is warranted here, and that warning would be that changing one part of the system means changing at least one or more parts of the system. Conducting a thorough review of existing treatments, expertise, and re

sources will help the change leader understand how the proposed new treatment will fit into the overall strategy and offerings of the practice. This will result in a more critical examination of the new approach and how it fits into the overall service delivery model of the agency, rather than its name or branding alone.

Once the desired treatment is vetted and determined to be the right one to achieve the long-term objectives of the organization and its patients, the focus shifts to how to implement its use. At this point, it is important to conduct a thorough review of existing implementation models and identify the approach that will allow the organization to successfully implement the new model in practice. Since implementation science is a fairly new paradigm in behavioral health, many providers do not have the expertise in choosing the appropriate model. The assumption is often made that being trained in the new approach alone is sufficient to effect organization-wide implementation. During training and implementation, many organizations do not establish feedback mechanisms so that 
successes and obstacles can be identified, methods modified, and improvements realized.

Both C. I. Lewis' theory of Conceptual Pragmatism [1] and Shewhart's and Deming's idea of the PDSA Cycle Plan, Do, Study, Act; [2] are grounded in continual review of theory and action (application) interacting with each other with the purpose of continual learning and improvement [3] . Lewis states that reality is not the given (sense date to be interpreted by the mind) itself, but the given categorically interpreted. Therefore, what the mind determines is not the content of reality; what it determines is the constraint on how the given will be interpreted. The framework, then, is the mind's imposition on its thinking of change, not the content of change. However, this framework is only probable, which implies that the mind's interpretation is only probable. This further implies that any approach to change is only probable. This is the context and content of any learning organization. The constant refining of what the mind brings to experience is crucial to understanding any reasonable success in change. This constant feedback loop is often rejected in favor of a viewpoint that considers implementation as an acute experience. Dr. Deming's retort to that approach is that experience unaided by theory teaches nothing. Experience unaided by theory teaches nothing in the sense that right answers, however temporal, or wrong answers, however definite, do not allow that pragmatic interplay of theory and practice. If something is unsuccessful, what does one change? If something is successful, what made it successful? Coincidence is also something that teaches nothing.

Managers establish timelines of when they will be "done", rather than understanding that integration is an on-going/long-term effort. This is a producer-centric mentality rather than a customer-centric orientation and has generally been viewed by even less innovative-thinking organizations as something that was learned by the mid-1990s. Most implementation efforts take years before the new model is fully integrated and sustainable. This is the fundamental thinking about the concept and practice of a learning organization. It also establishes the connection between leading and the leader being the intellectual caretaker of his/her organization, and learning, which is the vehicle for leaders to promote the organic nature of an innovative organization.

Another common mistake in new treatment implementation centers on the human resources involved. Often, leaders expect the person trained in the new approach to be responsible for its implementation across the organization. When this effort is not directed through the traditional command structure, the early adopter may quickly burn out if the new treatment is considered optional by others, or training on its implementation is not considered a priority. Not involving senior leadership in the implementation or even making them aware of the new service being provided lessens the urgency and priority across the organization. Not involving all affected parties in the change planning process results in mundane complications as well, such as not considering how existing paperwork and forms must be modified to accommodate the new service.
This of course is another example of anti-systemic thinking in the leadership arena. If the framework for organizational competitive advantage and thereby continuing success is leading, learning and change at a rate faster than your competition, Welch correctly decided that he needed a "leaderful" organization. He desired change leadership as much as change management. One is the engine of change, the other is the systems, and processes put in place to codify the change efforts. These barriers and a lack of information serve to increase frustration among providers and may foster resentment to the new service over time. In order to improve the ability of mental health organizations to effectively implement new treatments for their patients, several recommendations can be suggested. These center around strengthening the planning, communication, and feedback associated with the change. Other fundamental change-model approaches are too broad to discuss in this paper.

First, as mentioned earlier, the "how to change" or from earlier language in this paper, what the mind brings to experience, must be thoughtfully considered. Once the new treatment is determined to fill a need and fit with the service's mission and resources, the determination of how to create the change must be addressed. An organization's philosophy of change creates its practice of change. This philosophy brings an organization's rules of interpreting experience and the content of experience is the playing field for an organization's playbook. A number of implementation models should be reviewed to determine which fits with existing practice, policy and procedures. Once a structure for change implementation is identified, it becomes critical to make sure the correct employees are part of the process. Champions should be identified who are passionate about the new program and can act as advocates with other staff and leadership as needed.

In addition, an implementation team should be developed, which is representative of all affected employees, including management, therapists, front desk, etc. By involving all affected parties in a systemic approach to change management, we ensure that unintended consequences of our actions are identified and dealt with, and increase the commitment to the change by giving employees a role in its implementation. This team should be charged with identifying a way to pilot the new treatment and implementation methods. A pilot program will allow the organization to identify policy and procedural obstacles and develop appropriate solutions or amend existing services to accommodate the new treatment before attempting organization-wide implementation. For example, the team should consider how existing paperwork/policies/handbooks/advertising and billing/record-keeping procedures must be revised to include the new program.

The team should have a 'big picture' mindset for implementation and recognize that it requires a work-in-progress mentality with policy and procedural methods continuously being refined based on implementation successes and failures. Initially, the goal is not perfection, but to establish enough structure to fail in a survivable way. This survivability is the essence of a learning organization where the actual answer right or wrong is not more important 
than the learning process that constantly pursues perfection accepting failure as an important part of any experiment to uncover a new and better reality. Even if the correct new treatment is identified, and a strategic plan for its implementation is created, the effort could be a failure without a thoughtful communication plan. Communication of the organization's efforts must start with senior leadership, who regularly broadcasts their commitment to and confidence in the new treatment. This sets the stage for the implementation team to regularly communicate their progress and successes so all agency personnel are aware of the new service and how it can benefit their patients. Communication has to be as much a part of the implementation plan as the training on the treatment itself.

As the program gains traction, the team's effort must move from introduction to sustainability. Identifying highly skilled staff to serve as supervisors and eventually trainers for new staff as they become trained in the approach will aid in sustainability of the new intervention over time. Having a formal feedback loop will ensure that obstacles in codifying the new process will be identified and dealt with as they arise. The feedback loop should include regular assessment of whether the treatment itself is meeting the initial objectives, as well as assessment of whether the implementation process worked as planned. In short, organizations that reflectively analyze both what they do and how they do it, can maximize learning from these experiences, and improve the outcome with the next new process to be introduced.

This discussion of the challenges and recommendations for improving the planning, communication and feedback of new process implementation is not meant to be exhaustive, but rather serve as points of consideration and reflection for those considering implementing a new practice. The recommendation of the authors of this paper would be to uncover and make recommendations for a model that lessens the change failure rate from its current $50 \%$ $75 \%$ rate. This may be the greatest competitive break through any organization can make.

\section{References}

1. Carruthers P (1987) Conceptual pragmatism. Synthese 73: 205-224.

2. Deming WE (1993) The new economics. MIT Press, Cambridge, UK.

3. Langley G, Moen R, Nolan K, Nolan T, Norman C (2009) The improvement guide $\left(2^{\text {nd }} e d n\right)$, Jossey-Bass, San Francisco, USA.
Creative Commons Attribution 4.0 International License

For possible submissions Click Here
Submit Article

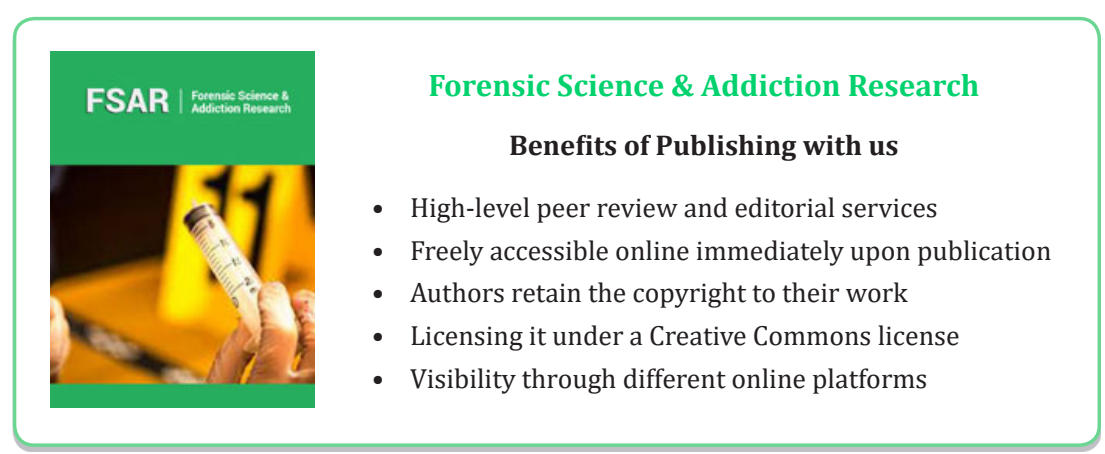

